\title{
On the Synoptic Structure of Typhoon Cora, 1969, as the Compound System of Tropical and Extratropical Cyclones
}

\author{
By Hiroshi Matano* \\ Nagoya Local Meteorological Observatory, J. M. A., Nagoya, Japan \\ and Mitsuru Sekioka \\ Institute of Meteorology, The Defense Academy, Yokosuka, Japan \\ (Manuscript received 7 August 1970, in revised form 26 April 1971)
}

\begin{abstract}
Typhoon Cora, 1969, took the extratropical appearance over the Japanese Islands. This aspect is analyzed from the view-point that Cora is the compound system of tropical and extratropical cyclones. The synoptic analyses show that the participant extratropical cyclone pre-existed independently far from Cora and approached Cora to form the compound system with her, and that it usurped Cora at last, resulting in her apparent extratropical transformation. This aspect is different from those, previously investigated as the complex system, in which the participant extratropical cyclone is induced on the pre-existing front which invades into the inner region of typhoon area. The synoptic behavior of participant extratropical cyclone of the compound system is brought into focus to confirm the condition favorable for its deve'opment.
\end{abstract}

\section{Introduction}

A hypothesis has been presented for the apparent transformation of a typhoon into an extratropical cyclone in middle latidudes that the typhoon does not transform herself into an extratropical cyclone but induce an extratropical cyclone on the preexisting front to form a complex system with it, and that the induced extratropical cyclone develops to usurp the typhoon, resulting in the apparent extratropical transformation of typhoon (Sekioka, 1956a). This hypothesis has been confirmed through the later investigations of typhoons (Sekioka, 1956b, 1959a, 1959b and 1970) and a hurricane (Matano, 1958b).

At that time when the hypothesis was first presented, the origin of the induced extratropical cyclone was not fully verified due to lack of data over the continental China in analyzing the apparent extratropical transformation of typhoon Marie, 1954, who caused the calamity of Ferryboat Toya-maru. Since then, the analyses of hurricane Hazel, 1954 (Matano, 1958b) and typhoon Babs, 1956 (Sekioka, 1959b) clarified the inducement of the participant extratropical cyclone on the pre-existing front which invades into a

\footnotetext{
* Present affiliation: T.I.A. Aviation Weather Service, J. M. A., Tokyo, Japan
}

typhoon or hurricane. It was also confirmed that a typhoon decaying out without an extratropical appearance was not accompanied by the induced extratropical cyclone, because the pre-existing front was so distant from a typhoon or such a front was absent (Sekioka, 1957).

However, another situation was experienced over the Japanese Islands that a pre-existing extratropical cyclone encountered with a typhoon and transformed the typhoon into an extratropical cyclone in appearance (Matano, 1965). This system is to be distinguished from the already mentioned complex system, because the participant extratropical cyclone is not induced by a typhoon but pre-exists without any direct relation to a typhoon. Though the role of participant extratropical cyclone played in the apparent extratropical transformation of a typhoon is all the same in these two systems, the genesis is quite different. Then the system is hereafter called the compound system in contrast with the complex system.

In the previous investigations, the concerned synoptic situations were so complicated to extract the characteristic features and to confirm the dynamical conditions favorable for the development of participant extratropical cyclone. On the contrary, the synoptic situation is relatively simple, in case of typhoon Cora, 1969, to treat the development of participant extratropical 
cyclone, because the immediate influence of a typhoon is seen to be feeble.

Typhoon Cora had the unusual course with a discontinuous turning over the northern part of Japan proper, therewith she redeveloped and was transformed into an extratropical cyclone in appearance. In the present paper, the aspect of apparent extratropical transformation of Cora is brought into focus from the view-point that Cora is the compound system. Before proceeding to the main subject, the general description is given in brief in the following section.

\section{General}

Typhoon Cora, who was born over the tropical Pacific northwest of Truck on 13th August, 1969, landed at Satsuma Peninsula, Kyushu, about 01 GMT 22nd August, via the Loochoo Islands. The central pressure was $960 \mathrm{mb}$ at landing. Since then, Cora travelled northeastward over the Japanese Islands, decaying to the central pressure of $986 \mathrm{mb}$ at 06 GMT 23rd over the northern part of Kanto. Thereafter she took her course discontinuously north-northeastward to the middle part of Tohoku at 12 GMT 23rd. During these 6 hours, Cora redeveloped to the central pressure of $982 \mathrm{mb}$ at 09 GMT and transformed herself into an extratropical cyclone in appearance accompanied by warm and cold fronts.

Fig. 1 shows the 6-hourly central positions of

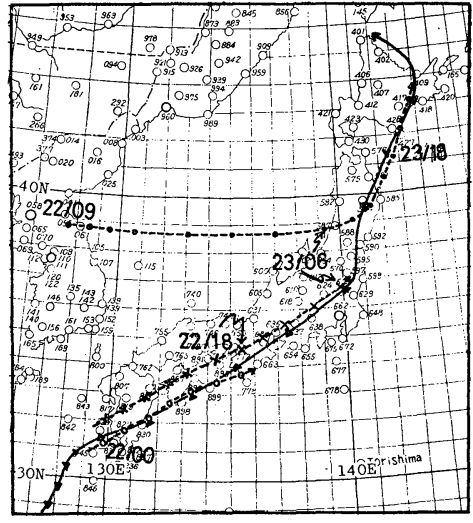

Fig. 1. Path of typhoon Cora. The 6-hourly central position (A-) of Cora (apparent). The 3-hourly positions of the typhoon vortex (-- --$)$, of the tropical vortex $(--\times--)$ and of the participant extratropical cyclone (-- - ).
Cora, reported by the Japan Meteorological Agency in the provisional publication. A series of synoptic situations near the Japanese Islands on the 850

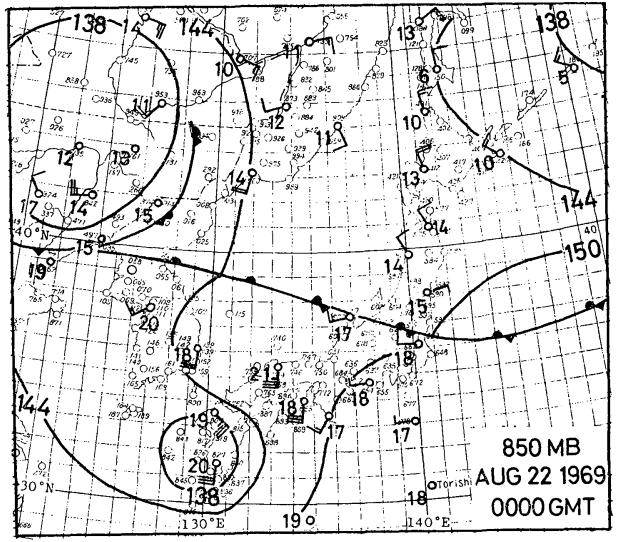

Fig. 2a. $850 \mathrm{mb}$ chart for 00 GMT 22nd August, 1969.

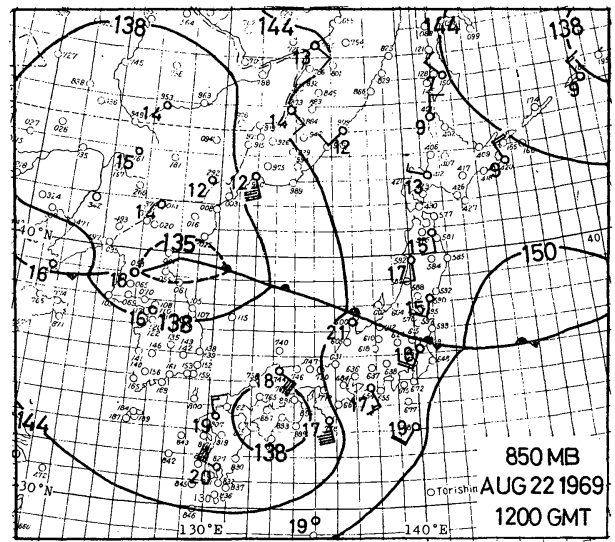

Fig. 2b. $850 \mathrm{mb}$ chart for 12 GMT 22nd August, 1969.

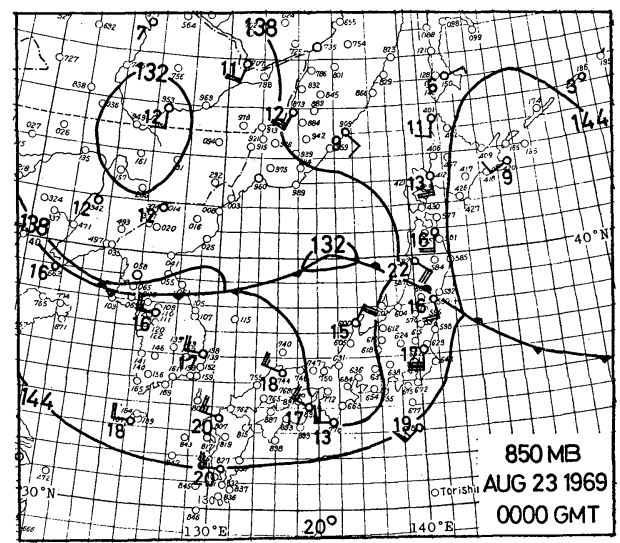

Fig. 2c. $850 \mathrm{mb}$ chart for 00 GMT 23rd August, 1969. 


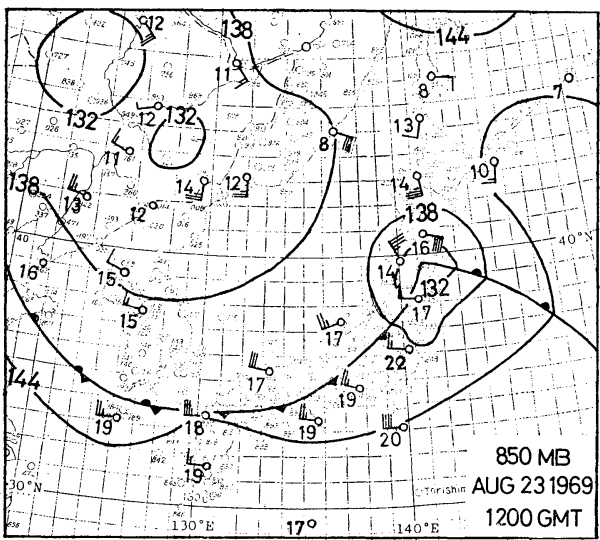

Fig. 2d. $850 \mathrm{mb}$ chart for 12 GMT 23rd August, 1969.

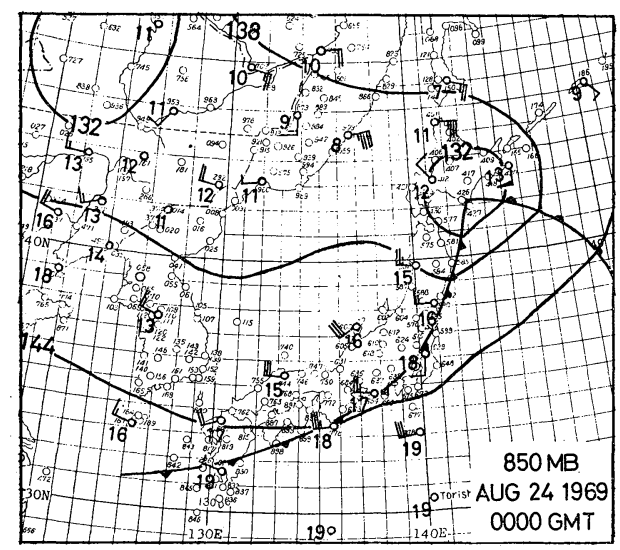

Fig. 2e. $850 \mathrm{mb}$ chart for 00 GMT 24th August, 1969.

$\mathrm{mb}$ charts prepared 12-hourly are given in Figs. $2 \mathrm{a}-2 \mathrm{e}$, to show the frontal features and the surrounding pressure field related to Cora in broad survey. A cold cyclonic vortex stayed over Manchuria, from 00 GMT 22nd to 00 GMT 24th, as seen in these figures. A nascent extratropical cyclone appeared at 12 GMT 22 nd on the preexisting front over the Korean Peninsula, lying between Cora near Japan and the cold vortex over Manchuria (Fig. 2b). This extratropical cyclone was not seen on the weather chart at 00 GMT 22nd (Fig. 2a). This cyclone developed during its eastward journey over the Japan Sea, approaching Cora who was decaying over the Japanese Islands in her northeastward journey (Figs. 2b and 2c). Cora is seen to be retained in the southward projection of $1380 \mathrm{gpm}$ contour at 12 GMT 23rd, which implies the compound system (Fig. 2d). The participant extratropical cyclone is seen to visit Hokkaido at 00 GMT 24th, via Tokoku, after its eastward journey along the latitude of 40 degrees in north over the Japan Sea (Fig. 2e).

The synoptic behavior of Cora over the Japanese Islands is characteristically classified into three phases as follows; the first phase is before 06 GMT 23rd and is of purely tropical nature, the second phase is from 06 GMT 23rd to 12 GMT $23 \mathrm{rd}$ and is of tropical and extratropical natures, and the third phase is after 12 GMT 23rd and is almost of extratropical nature. Of these phases, the principal interest of the present study is concerned with the second and third phases, to throw light on the aspect in which the typhoon has an extratropical appearance.

The synoptic characteristics in the first phase are all the same as those obtained in the previous studies cited in references (Namekawa and Aoki, 1936; Aoki, 1954; Matano, 1956a, 1957, 1958a, 1958b, 1960, 1965; Sekioka, 1956a, 1956b, 1959b). Here are mentioned only the important features, recapitulating the essential concept related to the present study. So the details are to be refered to the cited literatures.

A tropical cyclone comes into synoptic existence first as the tropical vortex, which develops gradually to maturity. A tropical cyclone evolves into a severe typhoon when the typhoon vortex breaks out spontaneously in the inner region of mature tropical vortex. The tropical vortex is a mother body of typhoon and it is a conservative system. The severity of typhoon originates from the typhoon vortex, which is a variable system embeded in the larger and taller tropical vortex. When such a typhoon, namely a tropical vortex accompanied by a typhoon vortex, hits the Japanese Islands, the typhoon vortex decays more or less rapidly, surviving the tropical vortex. The tropical vortex also begins to decay after the typhoon vortex dissipates out. While the typhoon vortex is intense, it overwhelms the pressure field of tropical vortex and the center of typhoon vortex stands for the apparent center of typhoon, resulting in the eccentricity of circular isobaric pattern. As the typhoon vortex decays, the tropical vortex restores its own pressure field and the center of tropical vortex appears in company with the center of typhoon vortex, resulting in the apparent two separate centers, and eventually stands for the apparent center of typhoon, therewith the eccentricity disappears. 
These circumstances are well represented also in the present case. As seen in Fig. 3a, there is exhibited the eccentricity. The outer circular isobars, say $992 \mathrm{mb}$ or $996 \mathrm{mb}$, are almost conserved in dimension, though the inner isobars are rapidly changed, some of them even disappearing. Fig. $3 \mathrm{~b}$ shows that there are two separate centers, the northside center being situated nearly on the geometric center of outer circular isobars and the southside center being situated on the course of typhoon so far traced as the apparent center of typhoon. The geometric center of outer isobars takes its course parallel to the apparent course of typhoon before two centers appear.

These circumstances are also seen on the 850 $\mathrm{mb}$ charts, as shown in Figs. 2a-2c. For example, the dimension of $1380 \mathrm{gpm}$ contour related to Cora is almost conserved and the apparent center is eccentric, compared with the geometric center of $1380 \mathrm{gpm}$ contour. As already mentioned, those are not the main topics of the present paper, but the basic concept on the evolution of tropical cyclone into a severe typhoon is recapitulated in relation to the present study, referring to the first phase of typhoon Cora.

It is noticed that the participant extratropical cyclone which came into existence over the Korean Peninsula was at that time so distant from typhoon Cora that the tropical vortex as well as the typhoon vortex had only a little influence upon the participant extratropical cyclone, and also that the typhoon vortex of Cora had almost dissipated out to survive the tropical vortex which had begun to decay when the participant extratropical cyclone came near to typhoon Cora. It is a very important aspect for the present study that the second phase of typhoon Cora started with these situations where the surviving tropical vortex had begun to decay.

\section{Analyses}

(i) Synoptic aspect

As mentioned in the foregoing section, the typhoon vortex of Cora had dissipated out on the weather chart at 00 GMT 23rd, thereafter Cora was only the tropical vortex which had begun to decay. Then the second phase, in which Cora took tropical and extratropical natures, began after 06 GMT 23rd.

In Figs. 3a-3d, the essential features of this phase are shown on the 3-hourly surface weather charts from 00 GMT 22nd to 00 GMT 24th.

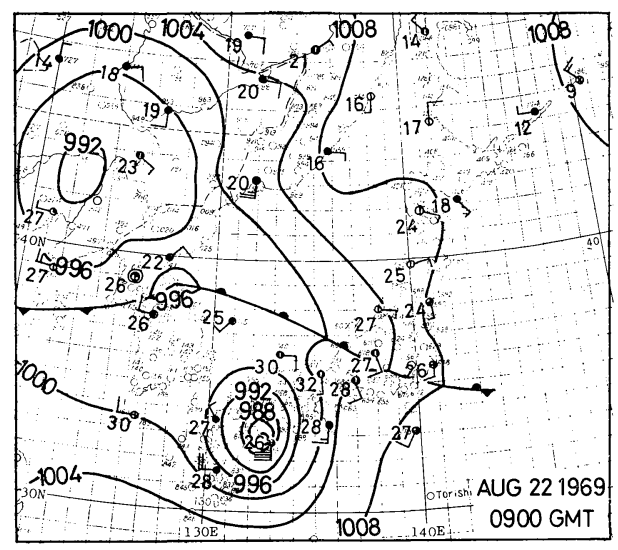

Fig. 3a. Surface weather chart for 09 GMT 22nd August, 1969.

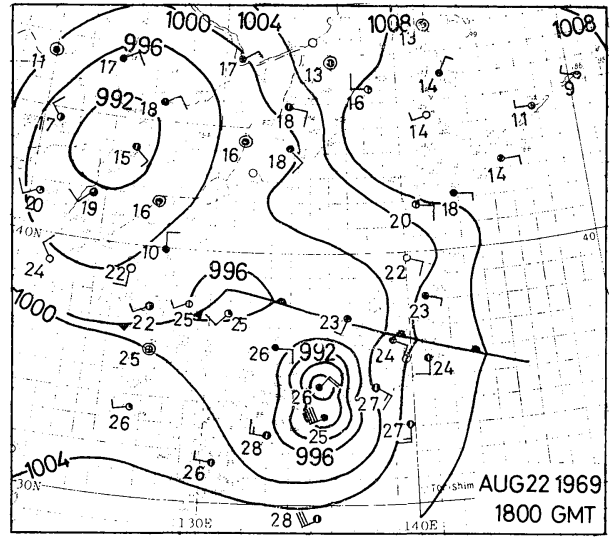

Fig. 3b. Surface weather chart for 18 GMT 22nd August, 1969.

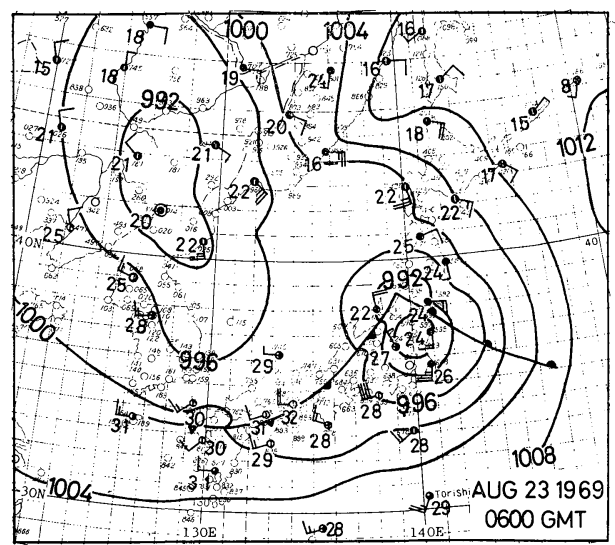

Fig. 3c. Surface weather chart for 06 GMT 23rd August, 1969. 


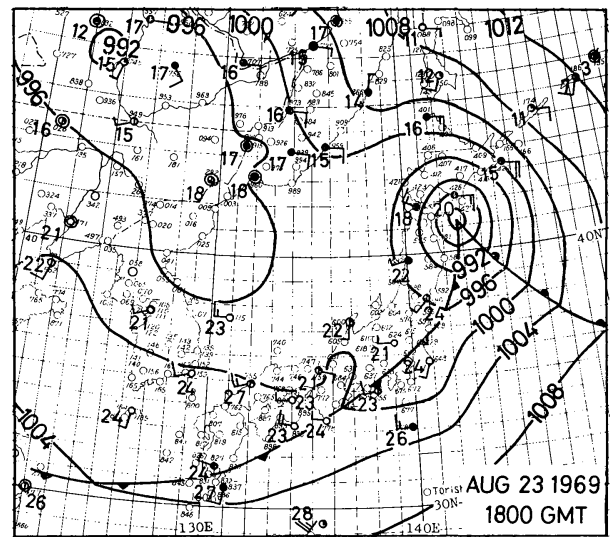

Fig. 3d. Surface weather chart for 18 GMT 23rd August, 1969.

The participant extratropical cyclone appeared over the East Korean Bay on the $850 \mathrm{mb}$ chart at 12 GMT $22 \mathrm{nd}$ can be traced on the surface chart at 09 GMT 22nd but not at 06 GMT 22nd. Thus the participant extratropical cyclone came into synoptic existence on the surface weather chart between 06 GMT and 09 GMT 22nd. It is also noticed that the East Korean Bay and its neighbourhood are known as the cradle of extratropical cyclone in summer.

As seen from Figs. $3 b$ and $3 c$, the participant extratropical cyclone travelled eastward over the Japan Sea to form the compound system with the tropical vortex at 06 GMT 23rd. The two separate pressure centers appeared on the surface weather chart at 06 GMT 23rd, where the northside center was clearly the center of extratropical cyclone and the southside center was the center of tropical vortex. As seen in Fig. 2d, the two separate centers appeared also on the $850 \mathrm{mb}$ chart at 12 GMT 23rd, where the southside center was implied in the southward projection of $1380 \mathrm{gpm}$ contour. This phenomenon of two separate centers is the typical features of the second phase, though the similar phenomenon being seen in the first phase as shown in Fig. $3 \mathrm{~b}$, which is also the typical feature of the first phase.

The participant extratropical cyclone can be recognized on the surface weather chart near the East Korean Bay before 18 GMT 22nd and also near the Japanese Islands after 03 GMT 23rd. On the other hand, it can be recognized over the Japan Sea on the ESSA 8 photomosaic at about 00 GMT 23rd as shown in Fig. 4. Thus

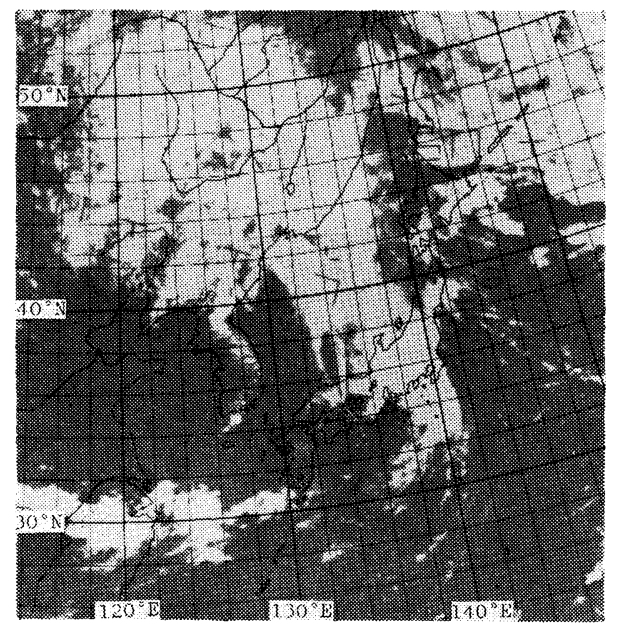

Fig. 4. ESSA 8 photomosaic at about 00 GMT 23rd August, 1969.

the participant extratropical cyclone can be confirmed to travel from the Korean Peninsula to the Japanese Islands traversing over the Japan Sea.

Separation of the pressure field of compound system into the pressure field of participant extratropical cyclone and that of tropical vortex is a difficult problem. In the present case, the pressure field of tropical vortex is removed from the actual field by the procedure used in the case of complex system (say, Sekioka, 1956a), as follows: The pressure-drop field of tropical vortex is assumed to be represented by the following formulae derived from the Rankine combined vortex,

$$
\begin{array}{ll}
p_{\infty}-p=\Pi\left[1-r^{2} /\left(2 b^{2}\right)\right] & \text { for } r \leqq b \\
p_{\infty}-p=\frac{1}{2}\left(\Pi b^{2} / r^{2}\right) & \text { for } r>b
\end{array}
$$

where $p_{\infty}$ is the pressure at the surrounding periphery, $p$ the pressure at the distance $r$ from the center of tropical vortex, $I$ the pressure-drop at the center of tropical vortex and $b$ the radius of inner region of tropical vortex. The parameters $p_{\infty}, b$ and $I I$ are to be determined from the known $p$ and $r$ at various places, using the method of least square. Here the following values are obtained; $p_{\infty}=1000 \mathrm{mb}, b=160 \mathrm{~km}$ and $\Pi=$ $16 \mathrm{mb}$ (before the tropical vortex begins to decay). Appropriateness of these parameters is verified by the synoptic fact that $p_{\infty}$ is almost equal to the pressure value of the outermost circular isobar, and by the physical relation between $\Pi$ and $b$ (Matano, 1956a), and further by the conservative 
nature of $b$, by the conservative nature of $\Pi$ during the typhoon vortex is alive, and by the damping mode of $\Pi$ after the typhoon vortex decays out (Matano, 1956a).

Thus the pressure-drop due to the tropical vortex at any time can be calculated and removed from the actual pressure field to obtain the pressure field free from the influence of tropical vortex. Fig. 5 shows an example of the calculated pressure field free from the influence of tropical vortex at 06 GMT 23rd, corresponding to Fig. $3 \mathrm{c}$, where the plausible pressure field of extratropical cyclone appears, and it is considered the pressure field due to the participant extratropical cyclone.

In Table 1, there are listed the central pressure of tropical vortex and participant extratropical cyclone calculated through the above mentioned procedure. For example, the central pressure, 986 $\mathrm{mb}$, of the participant extratropical cyclone at 09 GMT 23rd is influenced by the pressure-drop, 4 $\mathrm{mb}$, due to the tropical vortex at the center of participant extratropical cyclone and it is lowered

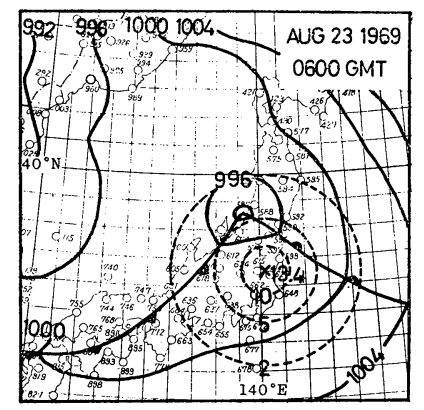

Fig. 5. Separated surface pressure patterns for 06 GMT $23 \mathrm{rd}$ August, 1969. Dashed lines are the isolines of the pressure-drop due to the tropical vortex, the center of which is indicated by $x$, and solid lines the isobars of the pressure field free from the influence of the tropical vortex. to $982 \mathrm{mb}$ in appearance. As seen from Table 1, the central pressure of participant extratropical cyclone before 06 GMT and after 12 GMT are almost the same as the apparent central pressure in the actual pressure field. This is considered to be due to the fact that the centers of tropical vortex and participant extratropical cyclone are so distant each other that the influences are very minute mutually.

The apparent central pressure filled until 06 GMT 23rd and redeepend from 06 GMT to 09 GMT, then filled again after 09 GMT. This is understood by considering that the monotonely decaying tropical vortex forms the compound system with the monotonely developing extratropical cyclone. When the central pressure of tropical vortex is deeper than that of participant extratropical cyclone, say at 06 GMT, the apparent center is taken at the center of tropical vortex. On the contrary, when the central pressure of participant extratropical cyclone becomes deeper than that of tropical vortex, say at 09 GMT, the apparent center is taken at the center of participant extratropical cyclone, resulting in the apparent redevelopment.

After 12 GMT 23rd, the tropical vortex decayed further and the participant extratropical cyclone usurped typhoon Cora at last as her successor, as seen in Fig. 3d. Thus the third phase began after 12 GMT 23rd. As seen in Table 1, the central pressure of participant extratropical cyclone ceased its further development after 15 GMT 23rd; it was of course reflected in the apparent variation of central pressure.

\section{(ii) Dynamic aspect}

The synoptic be.uvior of participant extratropical cyclone descrived in the foregoing paragraph is considered from the dynamic view-point, laying stress on the development of participant extratropical cyclone.

It is well known that cyclone development at

Table 1. Central pressures of typhoon Cora (apparent), tropical vortex (calculated) and participant extratropical cyclone. (in $\mathrm{mb}$ )

\begin{tabular}{|c|c|c|c|c|c|c|c|}
\hline 23rd August, 1969 & 00GMT & 03GMT & 06GMT & 09GMT & 12GMT & $15 \mathrm{GMT}$ & $18 \mathrm{GMT}$ \\
\hline Apparent central pressure of Cora & 984 & 985 & 986 & 982 & 984 & 982 & 982 \\
\hline Central pressure of tropical vortex & 984 & 985 & 986 & 988 & & & \\
\hline $\begin{array}{l}\text { Central pressure of extratropical } \\
\text { cyclone }\end{array}$ & 994 & 992 & 990 & 986 & 984 & 982 & 982 \\
\hline
\end{tabular}




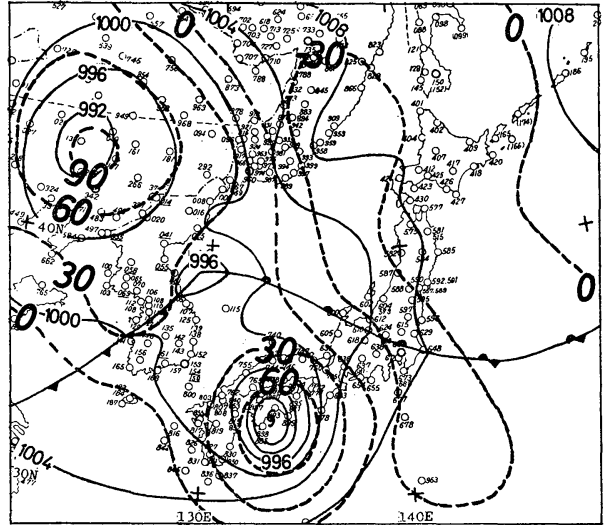

Fig. 6a. $500 \mathrm{mb}$ relative vorticity field (prepared by J. M. A.) superposed on surface weather chart for 12 GMT 22nd August, 1969. Dashed lines are isolines of relative vorticity (in $10^{-6} \mathrm{sec}^{-1}$ ).

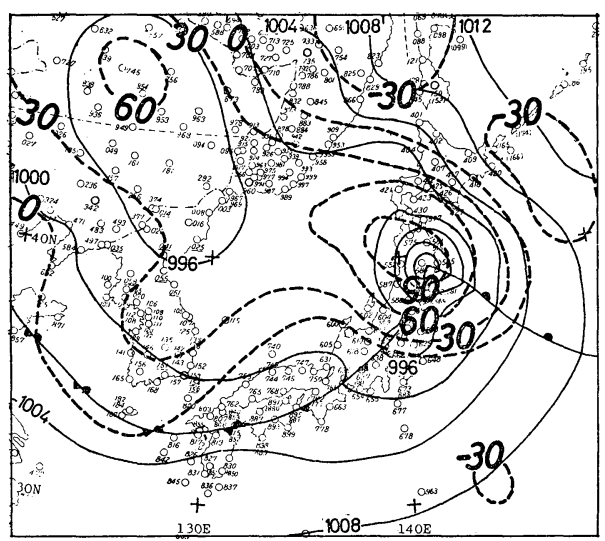

Fig. 6b. $500 \mathrm{mb}$-relative vorticity field superposed on surface weather chart for 12 GMT 23rd August, 1969.

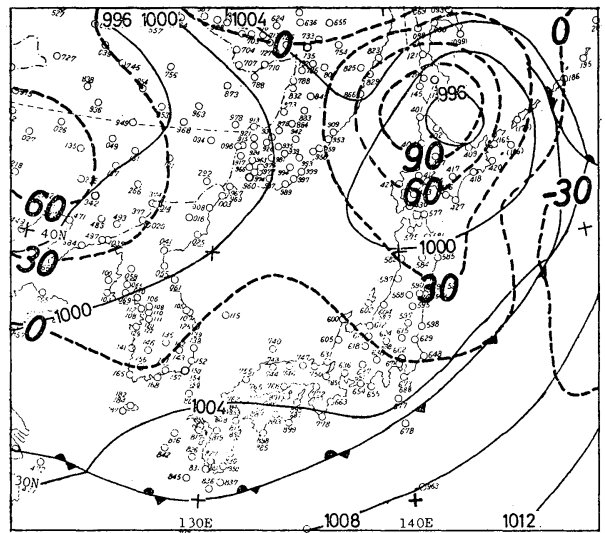

Fig. 6c. $500 \mathrm{mb}$-relative vorticity field superposed on surface weather chart for 12 GMT 24th August, 1969. sea level occurs when and where an area of appreciable vorticity advection in the upper troposphere becomes superposed upon a slowly moving or quasi-stationary front at sea level. This circumstance is well experienced in the present case, as shown in Figs. 6a-6c, where an area of positive relative vorticity of 9 to $6 \times 10^{-5} \mathrm{sec}^{-1}$ at the 500 $\mathrm{mb}$ surface can be traced, relating to the participant extratropical cyclone at sea level, from 12 GMT 22nd to 12 GMT 24th. At 12 GMT 23rd, the area of positive vorticity at the $500 \mathrm{mb}$ surface almost overtook the cyclone at sea level, implying that the appreciable further development of participant extratropical cyclone was not expected. In fact, that the participant extratropical cyclone at sea level continued to develop until 15 GMT 23rd, but ceased to develop since then, as shown in Table 1.

The successive positions of the $5700 \mathrm{gpm}$ contour at the $500 \mathrm{mb}$ surface, related to the participant extratropical cyclone, are shown in Fig. 7, from 00 GMT 22nd to 12 GMT 23rd. The wave-shaped contour represents the cold trough and the warm ridge as seen in Fig. 7, where the wave length is estimated about $3000 \mathrm{~km}$ as often experienced in the daily synopitcs. The contour ridge slows its eastward displacement after 00 GMT 23rd and is almost stationary over Hokkaido and Sakhalin, forming the blocking pattern after 12 GMT 23rd, as seen in Fig. 8. This situation influenced the eastward motion of the participant extratropical

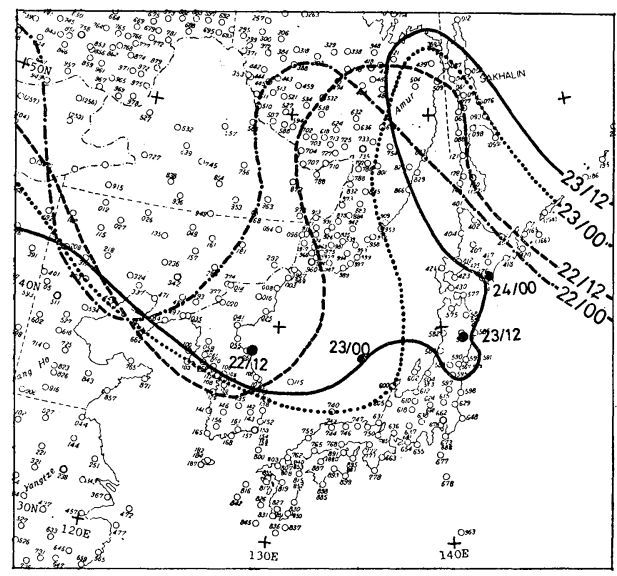

Fig. 7. Displacement of the wave-shaped $5700 \mathrm{gpm}$ contour of $500 \mathrm{mb}$ surface from 00 GMT 22nd to 12 GMT 23rd August, 1969 and the central position of participant extratropical cyclone at sea level (O). 


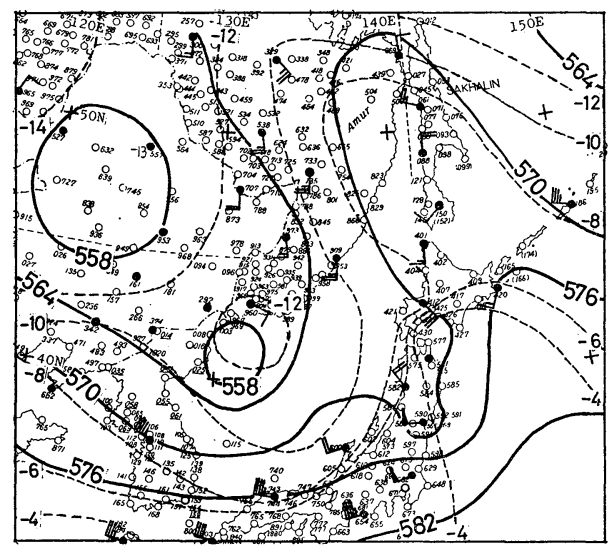

Fig. 8. $500 \mathrm{mb}$ chart for 12 GMT 23rd August, 1969.

cyclone embeded in the general current, and steered the motion northward as the result. In spite of the conspicuous wave-shaped pattern of the general current, the cyclone at sea level travelled straightly eastward over the Japan Sea, as seen in Fig. 1. This was probably to be favored well by the eastward displacement of the wave-shaped pattern of the general current over the Japan Sea until 00 GMT 23rd. The circumstance that the motion of the participant extratropical cyclone is to be almost eastward over the Japan Sea and to be nearly northward over the northern part of Japan proper is well represented in Figs. 6a-6c, accord$i_{n g}$ to the well-known dynamic principle that the motion of cyclonic pattern at sea level is similar to that of the positive relative vorticity pattern at the $500 \mathrm{mb}$ surface.

The synoptic behavior of typhoon Cora is similar to that of hurricane Hazel, 1954, famous for her remarkable extratropical transformation and her strong redevelopment. The participant extratropical cyclone of hurricane Hazel is considered to be formed on the pre-existing front from two different view-points; the first one is that the vorticity advection ahead of the advancing upper trough results in cyclone development (Hughes et al., 1955), and the second one is that the front invades into the inner region of the tropical vortex and induces a new extratropical cyclone on it to form the complex system (Matano, 1958b).

In the present case, the participant extratropical cyclone of Cora is formed on the pre-existing front by the process similar to the first of the above-mentioned two view-points. However, the situation in the present case is quite different from that of Hazel in the aspect that the front does not invade into the tropical vortex before the formation of participant extratropical cyclone. For reference, the situations related to Hazel are shown in Figs. 9a-9b, which are cited after Hughes et al. (1955) and are at the same time the incentives to the application of the complex system hypothesis (Matano, 1958b).

As seen from these examples, two separate centers and other related appearances, previously noticed, are understood to be inherent to the structural characteristics of the systems rather than to be accidental due to the topography and

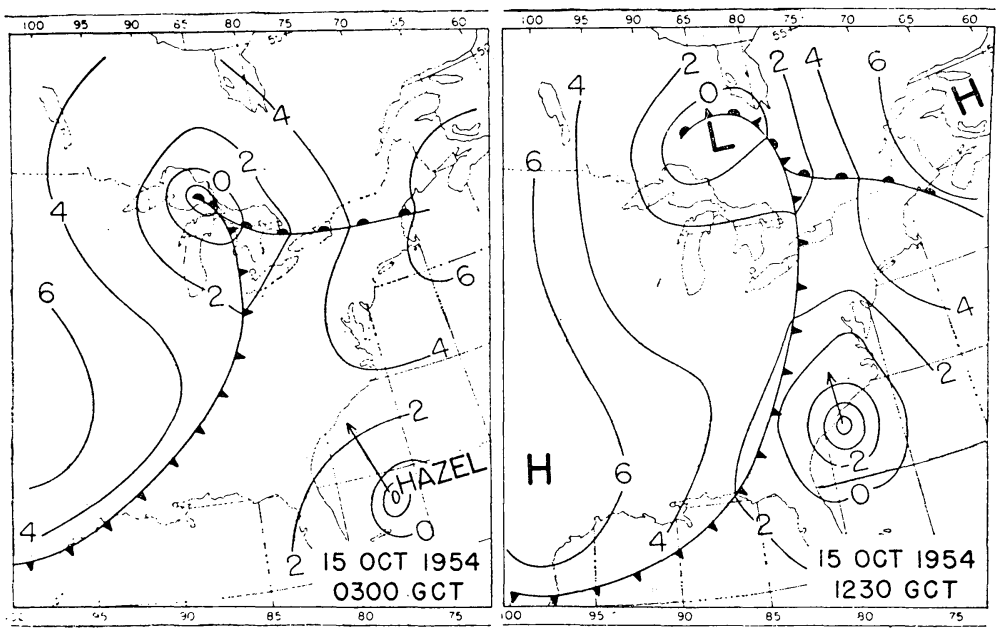

Fig 9a. Hurricane Hazel and the pre-existing cold front. (From Hughes et al., 1955.) 

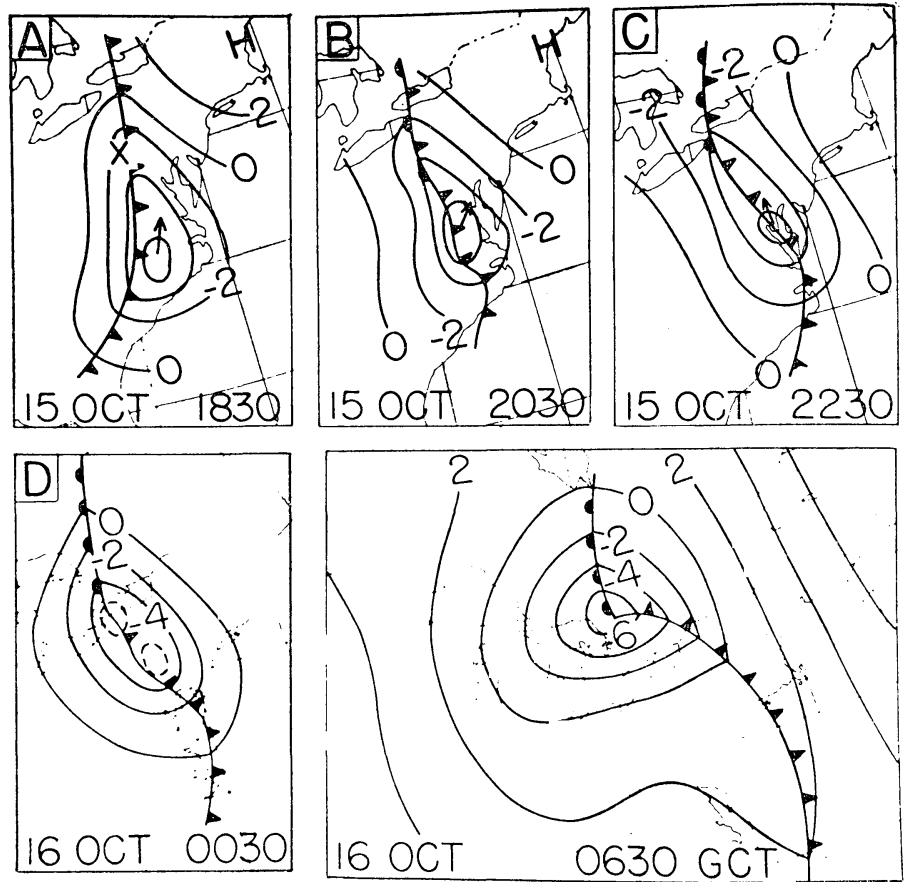

Fig. 9b. Extratropical transformation of hurricane Hazel.

(From Hughes et al., 1955.)

others. The present paper introduces the more obvious example on the apparent extratropical transformation of tropical cyclone in middle latitudes, focussing the formation and development of participant extratropical cyclone on the preexisting front, which does not invade into the tropical vortex, due to the vorticity advection ahead of the advancing upper trough, in the situation where the influence of tropical cyclone is feeble to extract easily the features of the participant extratropical cyclone. Thus the compound system is to be introduced in the nomenclature of a series of studies by the present authors, to discriminate it from the compiex system.

\section{(iii) Numerical consideration}

Here we consider dynamically the situation that the participant extratropical cyclone develops to its climax, while the tropical vortex continues to decay, in the compound system.

As seen in Figs. 10a and 10b, the extratropical cyclone was in whole situated under the area of ascending motion at 12 GMT 22nd, whereas at 12 GMT 23rd the fore-half of the cyclone was situated under the area of ascending motion and the rear-half under the descending motion. These imply that the cyclone was to be in the developing tendency at 12 GMT 22 nd and the cyclone was to be its climax at 12 GMT 23rd.

Fig. 11a shows clearly that the relatively warmer air ascended, whereas the relatively colder air descended, at 12 GMT 22nd, indicating that the potential energy decreased to increase the kinetic

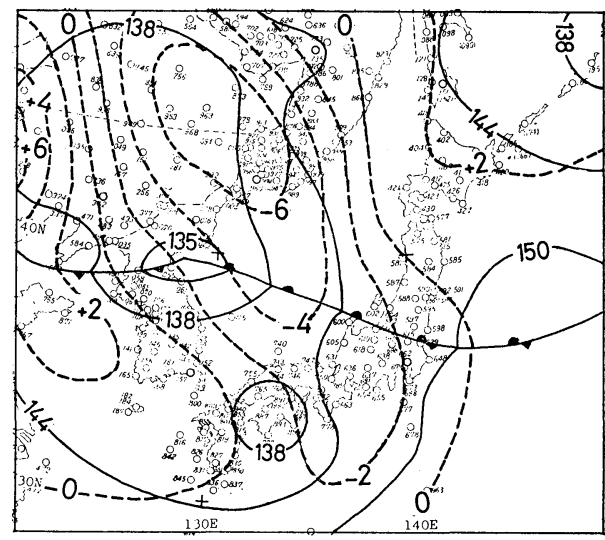

Fig. 10a. Vertical $p$-velocity field at $600 \mathrm{mb}$ (prepared by J.M.A.) superposed on $850 \mathrm{mb}$ chart for 12 GMT 22nd August, 1969. Dashed lines are isolines of vertical $p$-velocity (in $\mathrm{mb} \mathrm{hr}^{-1}$ ). 


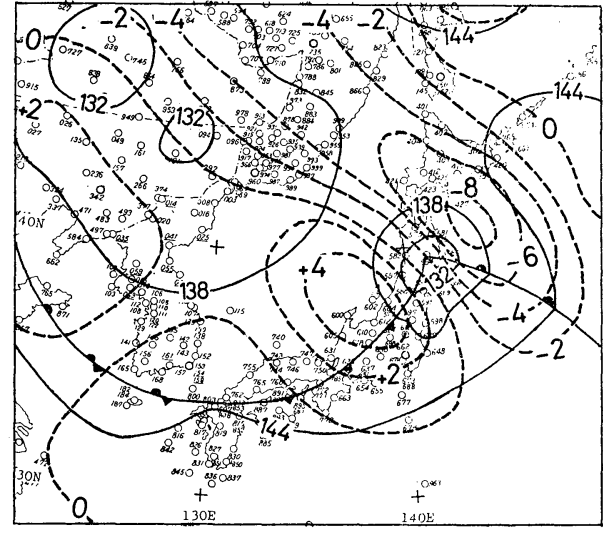

Fig. 10b. Vertical p-velocity field at $600 \mathrm{mb}$ superposed on $850 \mathrm{mb}$ chart for 12 GMT 23rd August, 1969.

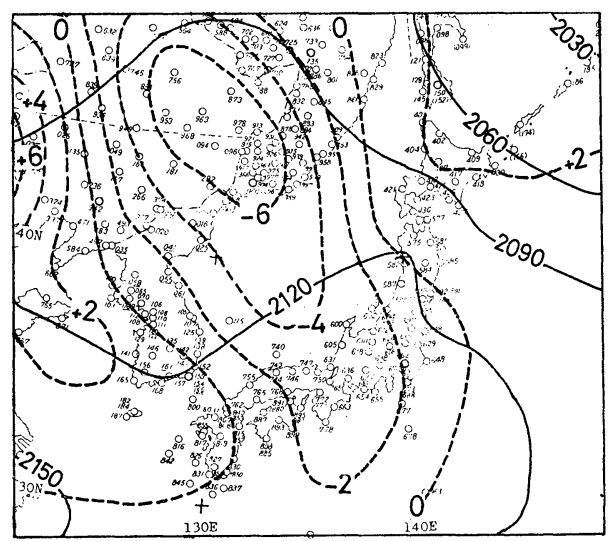

Fig. 11a. Vertical $p$-velocity field at $600 \mathrm{mb}$ and 700 to $900 \mathrm{mb}$ thickness pattern (prepared by J.M.A.) for 12 GMT 22 nd August, 1969. Dashed lines are isolines of vertical $p$-velocity, and solid lines are of thickness.

energy of the disturbance. In fact, the extratropical cyclone developed corresponding to this situation. On the other hand, Fig. $11 \mathrm{~b}$ shows that the relatively colder air ascended, whereas the relatively warmer air descended, at 12 GMT 23rd, indicating that the potential energy increased to decrease the kinetic energy of the disturbance. In fact, though the cyclone was still in the developing] tendency at that time, it soon began to decay after only 3 hours. These are well shown in the variation of the central pressure of the participant extratropical cyclone in Table 1.

As seen also in Table 1, the tropical vortex

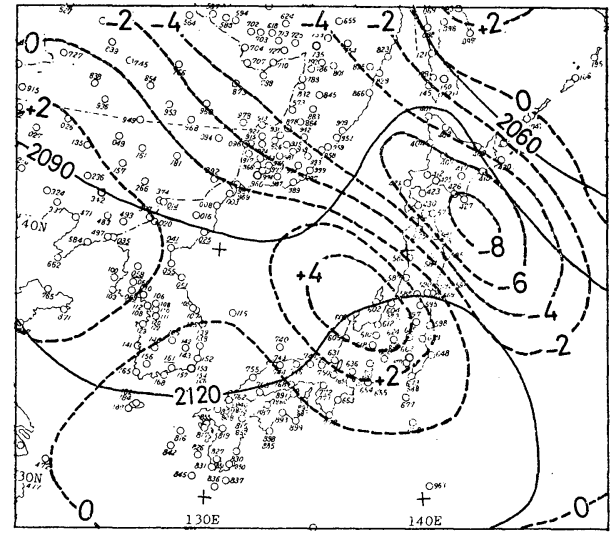

Fig. 11b. Vertical p-velocity field at $600 \mathrm{mb}$ and 700 to 900 mb-thickness pattern for 12 GMT 23rd August, 1969.

filled its central pressure by $6 \mathrm{mb}$ during 12 hours from $00 \mathrm{GMT} 23 \mathrm{rd}$ to $12 \mathrm{GMT} 23 \mathrm{rd}$. From this, we can calculate the decrease of kinetic energy of the tropical vortex, by assuming that the tropical vortex is almost in the cyclostrophic balance and its total kinetic energy is nearly represented by the tangential motion, through the followings: The fundamental equations are written in the conventional notation

$$
\begin{array}{ll}
\frac{v_{\theta}^{2}}{r}=\frac{\partial \phi}{\partial r} & \\
\phi=\phi_{\infty}-\frac{\Pi}{\rho}\left[1-r^{2} /\left(2 b^{2}\right)\right] & \text { for } r \leqq b \\
\phi=\phi_{\infty}-\frac{1}{2 \rho}\left(\Pi b^{2} / r^{2}\right) & \text { for } r>b \\
K=\frac{1}{2} v_{\theta}^{2}=\frac{1}{2} r \frac{\partial \phi}{\partial r} &
\end{array}
$$

where $\Pi / \rho=\phi_{\infty}-\phi_{c}$ and it is constant with height within the troposphere (Matano, 1956b). Then the kinetic energy $K^{*}$ of tropical vortex within the radius $r_{0}$ and the height $H$ is expressed

$$
\begin{aligned}
K^{*} & =\rho \int_{0}^{H} \int_{0}^{2 \pi} \int_{0}^{b} K r d r d \theta d z+\rho \int_{0}^{H} \int_{0}^{2 \pi} \int_{b}^{r_{0}} K r d r d \theta d z \\
& =\pi\left(\frac{1}{4}+1 \mathrm{n} \frac{r_{0}}{b}\right) \frac{\bar{\rho}}{\rho} \Pi b^{2} H
\end{aligned}
$$

where $\rho$ is the mean density of the air within the given volume of the total vortex.

Assuming that $\bar{\rho}=0.7 \times 10^{-3} \mathrm{gm} \mathrm{cm}^{-3}, H=10$ $\mathrm{km}, \quad r_{0}=660 \mathrm{~km}$ and $\rho$ (at sea level) $=1.0 \times$ $10^{-3} \mathrm{gm} \mathrm{cm}^{-3}$ and using the analyzed values of 
$b=160 \mathrm{~km}, \quad \Pi=16 \mathrm{mb}$ (at 00 GMT 23rd) and $\Pi=10 \mathrm{mb}$ (at 12 GMT 23rd), the kinetic energy of the tropical vortex is calculated by eq. (6) as follows;

$$
\begin{array}{ll}
K^{*}=15 \times 10^{24} \mathrm{erg} & \text { at } 00 \mathrm{GMT} 23 \mathrm{rd} \text { and } \\
K^{*}=9 \times 10^{24} \mathrm{erg} & \text { at } 12 \mathrm{GMT} 23 \mathrm{rd} .
\end{array}
$$

Thus the decrease of kinetic energy per unit time becomes

$$
\delta K^{*} / \delta t=-14 \times 10^{19} \mathrm{erg} \mathrm{sec}^{-1} .
$$

From the theoretical view-point, the variation of kinetic energy per unit mass is expressed in the conventional notation as follows;

$$
\frac{\partial K}{\partial t}=-v_{r} \frac{\partial K}{\partial r}-\omega \frac{\partial K}{\partial p}-v_{r} \frac{\partial \phi}{\partial r}+\chi
$$

or in the flux form

$$
\frac{\partial K}{\partial t}=-\frac{\partial\left(r v_{r} K\right)}{r \partial r}-\frac{\partial(\omega K)}{\partial p}-v_{r} \frac{\partial \phi}{\partial r}+\chi
$$

where $K=\frac{1}{2}\left(v_{r}^{2}+v_{\theta}^{2}\right)$ and $\chi=v_{r} F_{r}+v_{\theta} F_{\theta}$ (frictional term). Taking into consideration the boundary conditions of the atmosphere in the closed system, the first and second terms in the right hand side of eq. (8) vanish when eq. (8) is integrated over the whole region. Then eq. (8) becomes

$$
\begin{aligned}
\frac{\partial}{\partial t} \iiint K d A d p & =-\iiint v_{r} \frac{\partial \phi}{\partial r} d A d p \\
& +\iiint \chi d A d p
\end{aligned}
$$

The first term of the right hand side of eq. (9) corresponds with the production of kinetic energy or the work done by the pressure force, and the second term the frictional dissipation of kinetic energy. In the production of kinetic energy runs down, the kinetic energy must dissipate away through the frictional effect. Palmén et al. (1955) calculated the kinetic energy and the production of kinetic energy of a mean tropical cyclone within the radius of 6 degrees in latitudes, corresponding to the first term of the right hand side of eq. (9), and get

$$
\text { ca. } 12 \times 10^{24} \mathrm{erg}
$$

for kinetic energy and

$$
\text { ca. } 15 \times 10^{19} \mathrm{erg} \mathrm{sec}^{-1}
$$

for the production of kinetic energy of a mean tropical cyclone. Comparing this value with the value already mentioned for the decrease of the kinetic energy per unit time of the tropical vortex $\left(14 \times 10^{19} \mathrm{erg} \mathrm{sec}^{-1}\right)$, the order of magnitude is almost same in the opposite sign. It is therefore supposed that the tropical vortex of Cora decreased its kinetic energy at its own expense by the frictional dissipation due to the lack of the production of kinetic energy.

If the tropical vortex has no direct relation to the participant extratropical cyclone such as the tropical vortex behaves itself at its own expense as shown in the foregoing discussion, it is possible to estimate the energetics of the participant extratropical cyclone from the actual synoptic field of the compound system at 12 GMT 23rd. The production of kinetic energy or the work done by the pressure force is here calculated after Palmén (1958) for the area shown in Fig. 12. The area is divided into two blocks, the first and third quadrants, each being a rectangle of five degrees in latitude and in longitude in sides. The second and fourth quadrants are excluded, there being no observation of upper air. As seen in Fig. 10b, the blocks 1 and 2 almost represent favorably the ascending and descending areas respectively. The calculated results are shown in Table 2, comparing with Palmén's results for hurricane Hazel to ascertain the appropriateness of the present caluclation.

There being some discrepancy, these two sets of values are rather in good accordance in both the sign and the order of magnitude. The amount of increased kinetic energy in the block 2 is estimated about $50 \times 10^{19} \mathrm{erg} \mathrm{sec}^{-1}$, whereas the amount of decreased kinetic energy in the block

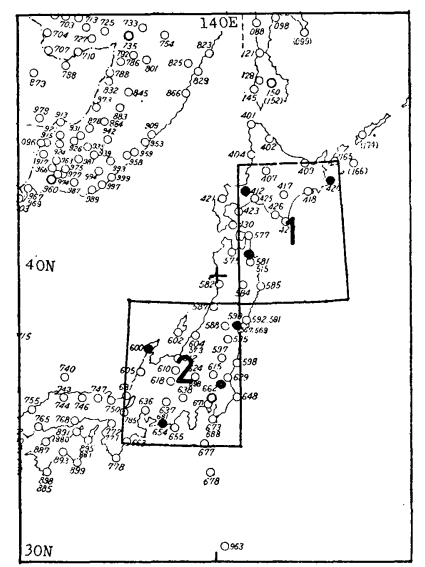

Fig. 12. Blocks used in the calculation of kinetic energy. indicates upper-air station. 
1 is about $25 \times 10^{19} \mathrm{erg} \mathrm{sec}-1$. The change of kinetic energy per unit mass is expressed in the rectangular coordinates as follows;

$$
\begin{aligned}
\frac{\partial K}{\partial t} & =-\left[\frac{\partial}{\partial x}(u K)+\frac{\partial}{\partial y}(v K)\right. \\
& \left.+\frac{\partial}{\partial p}(\omega K)\right]-\left(u \frac{\partial \phi}{\partial x}+v \frac{\partial \phi}{\partial y}\right)+\chi
\end{aligned}
$$

The present calculation is referred to the second term of the right hand side of eq. (10). This term is composed of the flux of potential energy and the conversion of potential energy as shown in the following equation;

$$
\begin{aligned}
-\left(u-\frac{\partial \phi}{\partial x}+v-\frac{\partial \phi}{\partial y}\right) & =-\left[\frac{\partial}{\partial x}(u \phi)+\frac{\partial}{\partial y}(v \phi)\right. \\
& \left.+\frac{\partial}{\partial p}(\omega \phi)\right]-\omega \alpha
\end{aligned}
$$

As already mentioned, the relatively colder air ascended in the fore-half and the relatively warmer air descended in the rear-half at 12 GMT $23 \mathrm{rd}$. Anyway in this situation, the potential energy increases, resulting in the decrease of kinetic energy of the disturbance in both the blocks 1 and 2. Comparing with the results shown in Table 2, it may be supposed that the inflow of potential energy excelled still the baroclinic effect of decrease of kinetic energy in the block 2 , while the baroclinic effect surpassed the

Table 2. Work done by the pressure forces unit: $10^{18} \mathrm{erg} \mathrm{cb}^{-1} \mathrm{sec}^{-1}$

\begin{tabular}{l||r|c||c|c}
\hline & Block 1 & $\begin{array}{c}\text { Palmén’s } \\
\text { value }\end{array}$ & Block 2 & $\begin{array}{c}\text { Palmén's } \\
\text { value }\end{array}$ \\
\hline $900 \mathrm{mb}$ & 0.08 & & 5.74 & \\
850 & -1.22 & 1.98 & 5.69 & 0.79 \\
800 & -1.26 & & 5.30 & \\
700 & -2.79 & 2.17 & 5.70 & 4.51 \\
600 & -4.54 & & 6.41 & \\
500 & -2.43 & -1.90 & 7.03 & 4.58 \\
400 & -3.47 & -0.12 & 8.03 & 4.78 \\
300 & -4.53 & -1.87 & 5.48 & 7.61 \\
200 & -4.98 & & 4.89 & \\
\hline
\end{tabular}

Block 1: $-A_{1} \int_{200}^{1000}\left(\bar{u} \frac{\overline{\partial z}}{\partial x}+\bar{v} \frac{\overline{\partial z}}{\partial y}\right) \delta p$ $=-23.92 \times 10^{19} \mathrm{erg} \mathrm{sec}^{-1}$

Block 2: $-A_{2} \int_{200}^{1000}\left(\overline{\bar{u}} \frac{\overline{\partial z}}{\partial x}+\bar{v} \frac{\overline{\partial z}}{\partial y}\right) \delta p$ $=+48.58 \times 10^{19} \mathrm{erg} \mathrm{sec}^{-1}$

( $A_{1}$ and $A_{2}$ are the area of blocks 1 and 2, respectively.) inflow of potential energy in the block 1 at that time.

It can be therefore concluded that the baroclinic effect dominates eventually the synoptic behavior in whole no matter how the flux of potential energy and also possibly the flux of kinetic energy are still active. The participant extratropical cyclone is thus supposed to have had begun to decay after 15 GMT 23rd under the predominance of the baroclinic effect to convert the kinetic energy into potential energy, inflicted by the frictional dissipation of its own property.

\section{Conclusion}

On the transformation of a typhoon into an extratropical cyclone, a hypothesis has been presented that the typhoon does not transform herself into an extratropical cycolne but induces an extratropical cyclone on the pre-existing front which invades into the typhoon area and forms a complex system with the induced extratropical cyclone which develops to usurp the decaying typhoon as her successor. Here is presented another mode of apparent extratropical transformation of typhoon, in which an independently pre-existing extratropical cyclone approaches the typhoon to form a compound system with her and usurps the decaying typhoon as her successor. The apparent extratropical transformation of typhoon Cora, 1969, is explained from the view-point that Cora is the compound system.

The synoptic behavior of typhoon Cora over the Japanese Islands is classified into three distinct phases. The first phase is purely of tropical nature before 06 GMT 23rd August, the second phase is of tropical and extratropical natures, representing the compound system, from 06 GMT to 12 GMT $23 \mathrm{rd}$ and the third phase is almost extratropical nature after 12 GMT 23rd. The participant extratropical cyclone pre-existed independently far from typhoon Cora and approached her. The participant extratropical cyclone developed in the fashion described in the typical baroclinic instability model. When the participant extratropical cyclone approached Cora to form the compound system with her, Cora was already in the decaying stage. Thus the participant extratropical cyclone usurped Cora in its own development embeded in the general situation where Cora had only insignificant contribution. The role and behavior of participant extratropical cyclone are definitely extracted in the apparent extratropical transformation of 
typhoon in the present case.

There may be more complicated situation for the apparent extratropical transformation of typhoon. For example, there may be potentiality to form the complex system even in the compound system, because the tropical vortex may induce another extratropical cyclone on the front accompanied by the participant extratropical cyclone in the compound system.

The inter-relation between the tropical vortex and the participant extratropical cyclone in these complicated situation is left to be studied as the future problem in use of some tractable examples.

\section{Acknowledgments}

The authors wish to express their hearty thanks to the Director of Nagoya Local Meteorological Observatory, J. M. A. and the Chief of Weather Central Service Squadron, JASDF for courtesies to supply them the valuable related data, to be analyzed and consulted, to the present study.

\section{References}

Aoki, S., 1954: On the structure of the disastrous typhoon hitting the Japanese Islands. Proc. UNESCO Symp., Tokyo, 1954, 61-76.

Hughes, L. A., F. Baer, G. E. Birchfield and R.E. Kaylor, 1955: Hurricane Hazel and a long-wave outlook. Bull. Amer. Meteor. Soc., 36, 528-533.

Matano, H., 1956a: On the role of the lateral mixing in the cyclostrophic flow pattern in the atmosphere. J. Meteor. Soc. Japan, 34, 125-136. , 1956b: A note on the vertical structure of typhoon. J. Meteor. Soc. Japan, 34, 288-292. , 1957: A synoptic study of the formation of the severe typhoon over the tropical ocean. $J$. Meteor. Soc. Japan, 35, 117-127.

, 1958a: A synoptic verification of the development of a tropical cyclone into a severe typhoon. J. Meteor. Soc. Japan, 36, 59-66. 1958b: On the synoptic structure of hurricance Hazel, 1954, over the eastern United States. J. Meteor. Soc. Japan, 36, 23-31.

- 1960: On the evolution of a tropical cyclone in relation to its life cycle. Mem. Kobe Marine Obs., (Horiguchi's Anniversary Volume) 14, 96-100.

- 1965: On the synoptic structure of typhoons, 1965, hitting the Japanese Islands. (unpublished).

Namekawa, T. and S. Aoki, 1936: A view of the structure of Muroto Typhoon. Mem. Coll. Sci., Kyoto Imp. Univ., 19, 79-91.

Sekioka, M., 1956a: Synoptic structure of typhoon Marie passing over the Japan Sea (A hypothesis on complex of tropical and extratropical cyclones for typhoon in middle latitudes). J. Meteor. Soc. Japan, 34, 276-287.

, 1956b: Synoptic structure of typhoons Louise, Kezia and Jane passing over the Japan Sea. J. Meteor. Soc. Japan, 34, 336-345. , 1957: Examples of typhoons not accompanied by extratropical cyclones in middle latitudes. J. Meteor. Soc. Japan, 35, 170-173.

1959a: Analysis on typhoons invading into the Japan Sea during the period from 1947 to 1956. J. Meteor. Soc. Japan, 37, 111-114.

1959: A synoptic study on formative stage of accompanying extratropical cyclone with reference to typhoon Babs. Mem. Osaka Univ. Liberal Arts and Ed., B, 8, 21-33.

- 1970: On the behavior of cloud patterns as seen on satellite photographs in the transformation of a typhoon into an extratropical cyclone. J. Meteor. Soc. Japan, 48, 224-233.

Palmén, E., 1958: Vertical circulation and release of kinetic energy during the development of hurricane Hazel into an extratropical storm. Tellus, 10, 123.

and C. L. Jordan, 1955: Note on the release of kinetic energy in tropical cyclones. Tellus, 7, 186-188. 


\title{
熱帯低気圧と温帯低気圧との重合系としての 台風 Cora (1969年) の構造の総観的研究
}

\author{
股野 宏 志* \\ 名古屋地方気象台
}

関岡満

防衛大学校・気象学研究室

台風 Cora (6909 号) の日本列島通過の際の状態を，8月23日15時（日本時間）以前の熱帯低気圧特性を示した期 間，23日15時〜21時の熱帯低気圧と温帯低気圧の両特性を示した期間，および23日21時以後の温帯低気圧特性を示し た期間に分けて, 総観的に研究した. 特に, 第 2 期の東北地方南部における経路と中心示度の急激な变化をともなう 台風の温帯低気圧化に解析の重点を置いた、日本列島上を衰弱しながら北東進した台風は, 台風から遙かに遠い朝鮮 半島方面から日本海上を発達しながら東進して来た温帯低気圧と23日午後から接近し, 重合系を形成し, 台風の減衰 とともに温帯低気圧が卓越し，見掛上の台風の温帯低気圧化が行われたと考えると，上述の急激な变化を系統的に説 明できることを示した，重合系を構成する温帯低気圧の発達に関して，うず度, 層厚, 垂直速度分布による考察と土 ネルギー計算を行った。

以上により，以前に多くの台風およびハリヶンの例で示した複合系—既存の前線が台風域内に侵入して，前線上 に温帯低気圧を発生させ，台風の衰弱とともにこの温帯低気圧が台風の後継者となり，見掛上の台風の温帯低気圧が 完成するといら——と異なる台風の温帯低気圧化の様式を明らかにした。

* 現在 : 東京航空地方気像台 